\title{
Políticas públicas para a biblioteca escolar e o fortalecimento da identidade regional brasileira: as contribuições do PNBE
}

\author{
Public Policies for the School Library and the Strengthening of Regional Brazilian Identify: \\ the contributions of PNBE
}

Ada Miriam Cabral
Ada Tecnologias pelo Instituto de Ensino Superior da FUNLEC. E-mail: adamirian_kilombola@hotmail.com

\begin{abstract}
Rodrigo Pereira
Doutorando e Mestre em Ciência da Informação pela UNESP, campus de Marília. Professor nos cursos de Pós-graduação em Gestão da Informação, do Conhecimento e Novas Tecnologias e Biblioteconomia do Instituto de Ensino Superior da FUNLEC. E-mail: rp121121@ hotmail.com
\end{abstract}

\begin{abstract}
Resumo
O artigo buscou verificar se o Programa Nacional Biblioteca da Escola (PNBE) tem contribuído para a construção da identidade regional brasileira por meio dos acervos selecionados e distribuídos para as bibliotecas escolares. A biblioteca escolar enquanto instrumento potencial de transformação e desenvolvimento social, só pode ser efetiva quando são estabelecidas políticas públicas para a sua manutenção. O PNBE, estabeleceu-se como uma política que visa subsidiar às bibliotecas escolares, acervos que tornem possível a sua eficácia. Caracterizado por selecionar e distribuir acervos de obras literárias, obras de atualização e de fomento à leitura é, portanto, o único recurso de composição e atualização das coleções para a grande maioria das bibliotecas escolares da rede pública de ensino. Os critérios do PNBE estabelecidos anualmente defendem assim, uma diversidade textual e temática das obras selecionadas, visando representar por meio das coleções o multifacetamento da sociedade brasileira. A pesquisa de caráter exploratório, utilizou-se dos métodos descritivo, comparativo e qualitativo com o uso da análise de conteúdo, buscando contemplar toda a complexidade do programa. Através da pesquisa documental, por meio dos documentos oficiais do programa, os dados foram coletados. A partir dos dados percebeu-se que há uma boa distribuição entre obras nacionais e internacionais, clássicos, contemporâneos e gerais. Dentre as obras que representam a cultura regional há a predominância de contextos urbanos e da região sudeste, ainda que estes sejam diversificados quanto a diversidade cultural que os compõe.
\end{abstract}

Palavras-chave: Biblioteca Escolar. Políticas Públicas. Programa Nacional Biblioteca da Escola.

\begin{abstract}
The article sought to verify if the National Library Program of the School (PNBE) has contributed to the construction of the Brazilian regional identity through the collections selected and distributed to the school libraries. The school library as a potential tool for social transformation and development can only be effective when public policies are established for its maintenance. The PNBE, was established as a policy that aims to subsidize to the school libraries, collections that make possible its effectiveness. Characterized by selecting and distributing collections of literary works, updating works and promoting reading, it is therefore the only resource for the composition and updating of collections for the great majority of school libraries in the public school system. The PNBE criteria established annually thus defend a textual and thematic diversity of the selected works, aiming to represent through the collections the multifaceted Brazilian society. The exploratory research used the descriptive, comparative and qualitative method with the use of content analysis, aiming to contemplate all the complexity of the program. Through the documentary research, through the official documents of the program, the data were collected. From the data it was noticed that there is a good distribution between national and international works, classic, contemporary and general. Among the works that represent the regional culture there is a predominance of urban contexts and the southeast region, although these are diversified as to the cultural diversity that composes them.
\end{abstract}

Keywords: School Library. Public policy. National School Library Program.

Bibl. Esc. em R., Ribeirão Preto, v. 6, n. 1, p. 18-42, 2018.

DOI: 10.11606/issn.2238-5894.berev.2018.130399 


\section{Introdução}

Na era da globalização, onde a barreira tempo e espaço foi rompida, proporcionando a interação entre culturas antes intocáveis, o desenvolvimento das nações será o que definirá sua posição na ordem social que se impõe. A questão que se coloca é que para se construir uma nação, é necessário utilizar a educação como instrumento de equiparação e igualdade social, principalmente quando se trata de uma nação composta por diversas identidades culturais regionais, que juntas formam a diversidade cultural que a caracteriza.

Para que a educação, portanto, seja ativa em proporcionar um desenvolvimento tanto individual, quanto social, pressupõe-se a formação do educando utilizando-se dos multivariados instrumentos educativos que a compõe. A biblioteca escolar pode, e deve ser um desses instrumentos, potencializando o aprendizado, sob uma perspectiva históricocultural desde as primeiras fases do processo de escolarização do indivíduo, pois, quando efetivamente desenvolvida, é capaz de proporcionar momentos que socializam e fomentam a própria diversidade cultural brasileira. A realidade que se estabelece no Brasil, infelizmente, é de escolas desestruturadas e bibliotecas cuja existência perpassa apenas por uma sala de leitura, quando esta não acaba por tornar-se um depósito de materiais desatualizados (quando existem) sem condições de uso, que não proporcionam o aprimoramento do aluno. Para subsidiar a formação do acervo das bibliotecas escolares da rede pública de ensino, o Ministério da Educação e do Desporto criou no ano de 1997 o Programa Nacional Biblioteca da Escola (PNBE).

O PNBE passou de um programa de curto prazo, inicialmente idealizado para durar apenas três anos, para uma política pública que atravessou três governos diferentes, nos últimos 19 anos. O programa tem por principais características a aquisição e distribuição de obras literárias para a atualização do professor, e fomento à leitura.

O programa proporciona às escolas cadastradas de todo o Brasil receberem as coleções selecionadas por meio dos editais anuais de seleção que estabelecem as especificações de cada edição. Em suma, os critérios estabelecidos nos editais buscam a diversidade dentro das obras selecionadas, seja quanto a qualidade textual, proporcionando diferentes níveis de dificuldade para o trabalho individual e mediado, bem como no que diz respeito às temáticas sociais e culturais, buscando representar os nichos existentes dentro da sociedade brasileira, seja na diversidade como na identidade cultural que a compõe. 
Políticas públicas para a biblioteca escolar e o fortalecimento da identidade regional brasileira: as contribuições do PNBE

Assim sendo, o que se buscou, foi perceber se o PNBE como uma política pública, tem contribuído para a construção da identidade regional brasileira por meio dos acervos selecionados, distribuídos para as bibliotecas escolares, e disponibilizado pelas mesmas de maneira efetiva. Portanto, através da sistematização do programa e de seus objetivos, da análise comparativa entre os critérios estabelecidos para a seleção e parte das obras selecionadas para distribuição às escolas no ano de 2013 que se encontravam acessíveis aos alunos, foi possível perceber a contribuição do PNBE na construção da identidade regional brasileira através dos acervos das bibliotecas escolares.

A pesquisa de caráter exploratório utilizou-se da análise de conteúdo para estudar os contextos explorados nas obras selecionadas, e perceber sua contribuição efetiva. A coleta de dados ocorreu por meio de pesquisa documental, nos documentos oficiais do programa, portarias, editais e ainda em parte das obras selecionadas e distribuídas às bibliotecas escolares, conforme identificadas no tópico material e métodos.

Ao analisar os dados coletados foi possível perceber que o programa contempla obras nacionais e internacionais, e ainda clássicos, contemporâneos e obras de cunho geral. Dentre as obras que representam a cultura brasileira, percebeu-se a predominância de contextualização urbana e da região sudeste, mas por outro lado notou-se a diversidade cultural existente. Mesmo que em menor número, há ainda obras que evidenciam as realidades de comunidades indígenas, quilombolas, ribeirinhas e rurais.

\section{Caracterizando o programa nacional biblioteca da escola - PNBE como uma política pública}

Toda nação deve prezar por seu povo enquanto capital humano essencial para o seu próprio desenvolvimento. O Brasil, por sua vez, sendo um país multifacetado, composto por uma sociedade multicultural, tem encontrado obstáculos a serem transpostos nesse sentido, desde o período imperial, pois "embora vivendo na sociedade da informação, o acesso a esta informação está abaixo do desejável" (ROSA, 2006, p. 192).

Como afirma Buarque (2006, p. 40) “em qualquer país, a educação é o instrumento principal de construção da identidade nacional e da igualdade social", mas será que esta tem sido a realidade brasileira, ou o autor está correto quando continua dizendo que "no Brasil, 
entretanto, a educação vem sendo instrumento da construção da desigualdade"? Se esse pressuposto é verdadeiro, o que deve ser feito para que o cenário seja transformado?

Para Marques Neto (2006, p. 28) é necessário estabelecer:

[...] políticas que garantam maior e melhor acesso à escola, às bibliotecas e aos livros, em todos os seus suportes materiais (papel ou tela), reconhecendo o valor social da leitura e o papel central que ela exerce no desenvolvimento humano, socioeconômico e cultural de uma nação.

Mas que políticas são essas? São aquelas em que o Estado intencionalmente age junto à sociedade (BELLONI; MAGALHÃES; SOUZA, 2000), e vale ressaltar que não basta a existência da mesma se a ação propriamente dita não alcançar os objetivos traçados. É preciso ainda, como defende Alencar (2006, p. 35),

[...] romper com a descontinuidade de políticas consideradas de interesse público, que quase sempre, são alteradas nominalmente e, por vezes, por mesquinharia política, minimizadas ou esvaziadas, quando um bloco partidário até então de oposição alcança o poder.

"Uma política pública reflete a vontade de diferentes setores da sociedade em avançar para uma determinada direção e representa uma articulação coerente de medidas para transformar uma situação" (ROSA, 2006, p. 185) e, portanto, visa sanar as disparidades existentes até então.

O acesso à escola, por si só, não é o suficiente para mudar a realidade da sociedade, são necessárias intervenções significativas na construção da identidade cultural, e para tanto será necessária uma Política de Estado que perceba na leitura e no livro, eixos estruturantes da sociedade, verdadeiros marcos de sua identidade cultural (MARQUES NETO, 2006).

"[A biblioteca] é o lugar que vai possibilitar aos alunos familiarizarem-se com a riqueza informacional hoje produzida pela sociedade e, consequentemente, com todo o mundo letrado" (CAMPELLO, 2003, p. 52), isso quando esta é pensada estrategicamente. Campello (2003) defende que a biblioteca escolar é um elemento chave de transformação social, enquanto espaço coletivo, ao oferecer as oportunidades para o exercício da cidadania, por ser o local onde o leitor crítico é formado, e onde a valorização e preservação da cultura serão entendidas e discutidas mediante a ampliação das experiências, da produção e do compartilhamento cultural gerado por meio da leitura. 
Políticas públicas para a biblioteca escolar e o fortalecimento da identidade regional brasileira: as contribuições do PNBE

Inegavelmente, a biblioteca é potencialmente revolucionária, mas, "quase não se tem notícia de medidas governamentais que visem à elevação das condições de funcionamento das bibliotecas das nossas escolas" (SILVA, 1995, p. 12).

"As primeiras ações voltadas para a biblioteca escolar e para o incentivo à leitura e à formação de leitores, como o Programa Salas de Leitura, tiveram início nos anos oitenta" (BRASIL, 2008, p. 5), e historicamente percebe-se que a distribuição de livros tem sido o modelo de intervenção que visa melhores condições de inserção dos alunos das escolas públicas na cultura letrada, no momento de sua escolarização (BRASIL, 2008).

Como parte de uma política de formação de leitores, em 1997, foi instituído o PNBE, pelo então Ministro da Educação e do Desporto, Paulo Renato Souza, através da Portaria Ministerial n. 584, de 28-4-1997, ao perceber:

[...] a necessidade de oferecer aos professores e alunos de ensino fundamental um conjunto de obras literárias e textos sobre a formação histórica, econômica e cultural do Brasil, além de obras de referência; a importância de apoiar técnica e materialmente os programas de capacitação para docentes que atuam no ensino fundamental (BRASIL, 1997).

Inicialmente, o PNBE foi criado como um programa de curto prazo, para "formar e qualificar as bibliotecas escolares, com o propósito de oportunizar aos alunos das escolas públicas o contato com a leitura literária" (FERNANDES; CORDEIRO, 2012, p. 319-320), dentro de três anos, com recursos provenientes do orçamento do Fundo Nacional do Desenvolvimento da Educação (FNDE) (BRASIL, 1997), mas transformou-se em uma política pública, ao perdurar por quase 20 anos e atravessar três mudanças de governo (FERNANDES; CORDEIRO, 2012).

O programa tem por característica básica a aquisição de obras de literatura brasileira, de formação histórica, econômica e cultural, de obras de referência e materiais de apoio, a formação continuada e atualização do professor, e o apoio a programas de incentivo a leitura (BRASIL, 1997), e para tanto o acervo em questão é composto "pelos seguintes gêneros literários: obras clássicas da literatura universal; poema; conto, crônica, novela, teatro, texto da tradição popular; romance; memória, diário, biografia, relatos de experiências; livros de imagens e histórias em quadrinhos" (BRASIL, [2014?]a).

O programa é executado em parceria pelo FNDE com a Secretaria de Educação Básica do Ministério da Educação, suas ações são executadas de forma centralizada, contando apenas com o apoio logístico das instâncias estaduais e municipais e instituições de ensino, após a 
definição dos critérios de avaliação e atendimento e da verificação da disponibilidade de recursos orçamentários (BRASIL, [2014?]a).

A distribuição dos acervos às escolas é realizada em anos alternados, educação infantil, anos iniciais do ensino fundamental e educação de jovens e adultos em anos pares, e anos finais do ensino fundamental e do ensino médio em anos ímpares (BRASIL, [2014?]c). Todos os anos são estabelecidos pelo FNDE, os critérios e regras para a seleção e avaliação das coleções a serem selecionadas, e estas são publicadas no Diário Oficial da União. A avaliação e a seleção são realizadas por equipes de mestres e doutores de universidades federais que possuam múltiplas experiências profissionais, incluindo docência na educação básica e a formação de professores (BRASIL, [2014?]c).

Após a seleção, a negociação e aquisição ocorrem diretamente com as editoras detentoras dos direitos autorais das obras, conforme previsto na Lei $n^{\circ}$ 8.666/93, que após firmar contrato iniciarão a produção (BRASIL, [2014?]c). Toda a produção é supervisionada integralmente pelos técnicos do FNDE, e posteriormente, é realizado o controle de qualidade (em acordo com as normas da ABNT e ISO) pelo Instituto de Pesquisas Tecnológicas. Por fim a distribuição é realizada diretamente das editoras às escolas através da Empresa Brasileira de Correios e Telégrafos (ECT) (BRASIL, [2014?]c).

Segundo as estatísticas apresentadas pelo FNDE, nos anos de 2013 e 2014 (ciclo completo de distribuição) foram investidos, para a compra de obras literárias a serem distribuída às escolas, $\mathrm{R} \$ 86.381 .384,21(2013)$ e $\mathrm{R} \$ 92.362 .863,86$ (2014); para a compra de periódicos, R\$ 57.072.470,94(2013) e R\$ 58.477.152,20 (2014), e para a formação continuada de professores no ano de 2013, R\$ 104.601.156,59 (BRASIL, [2014?]b). Percebese que há um investimento significativo no que diz respeito à execução do PNBE, uma vez que, desde a primeira distribuição em 1998 os valores aplicados são continuamente reajustados para ampliar o atendimento do programa, objetivando alcançar todas as escolas públicas do país.

Para que a efetividade do PNBE seja alcançada é necessária a sua constante avaliação, pois esta “[...] pode oferecer informações não apenas sobre impacto, mas sobre resultados ou consequências mais amplas e difusas das ações desenvolvidas" (BELLONI; MAGALHÃES; SOUZA, 2000, p. 9, grifo do autor) tornando-se assim "instrumento fundamental para a tomada de decisão e para o aperfeiçoamento ou reformulação das ações desenvolvidas" (BELLONI; MAGALHÃES; SOUZA, 2000, p. 9), uma vez que “[...] entende-se avaliação 
Políticas públicas para a biblioteca escolar e o fortalecimento da identidade regional brasileira: as contribuições do PNBE

como um processo sistemático de análise de uma atividade, fatos ou coisas que permite compreender, de forma contextualizada, todas as suas dimensões e implicações, com vistas a estimular seu aperfeiçoamento" (BELLONI; MAGALHÃES; SOUZA, 2000, p. 15, grifo do autor).

Apresentar-se-ão a seguir, portanto, os critérios de seleção estabelecidos pelos gestores do programa através dos editais, pois "[...] a análise do conteúdo e documentos tem por objetivo contribuir para a explicitação do texto escrito e do seu discurso ideológico, buscando esclarecer os significados e implicações das proposições consubstanciadas nas diretrizes, estratégias e linhas de ação da política” (BELONI; MAGALHÃES; SOUZA, 2000, p. 55), elementos essenciais para a avaliação da contribuição social do PNBE para a construção e fortalecimento da identidade regional brasileira.

\section{O processo de seleção de acervos desenvolvidos pelos gestores do PNBE: critérios e considerações}

Para Silva (1995) o paradigma de ensino e aprendizagem apenas por meio do livro didático ou de aulas somente expositivas, tem limitado a participação de outros elementos. A missão da escola, não se resume à transferência de um saber elaborado, mas sim em "que possa formar cidadãos críticos, capazes de utilizar criticamente o conhecimento construído na escola para analisar o real e, diante dele, fazerem as suas opções profissionais, culturais e políticas, de forma consciente, livre e autônoma." (SILVA, 1995, p. 18).

É a biblioteca escolar que pode e deve ocupar um lugar destacado ao tornar-se uma agência disseminadora do saber (SILVA, 1995), "ela é, portanto, o espaço ideal para reunir a diversidade textual que existe fora da escola e que deve estar a serviço da expansão do conhecimento letrado do aluno" (CAMPELLO, 2003, p. 52), para isso, sua coleção não pode se resumir a reunião de materiais aleatórios, e sim ser pensada, formada e desenvolvida com critério, tendo sempre em consideração o contexto em que esta se insere (ABREU, 2003).

Segundo Vergueiro (2010) alguns critérios abrangentes devem ser considerados durante o processo de seleção em qualquer biblioteca, e são eles: o assunto, o usuário, o documento e o preço. Quanto ao assunto, o autor afirma que deve haver ordem de prioridades quanto a este aspecto, para que a coleção seja adequada ao seu contexto; o usuário deve ser considerado para que os seus interesses e necessidades informacionais sejam atendidos de 
maneira eficaz; o tipo e a qualidade do documento devem ser avaliados para que a coleção seja a mais completa possível, e ao mesmo tempo evitar o desperdício de recursos, e por fim o custo sempre será um dos critérios relevantes, uma vez que não é possível ter tudo o que se almeja, principalmente com o aumento exponencial da produção da informação.

O PNBE, para algumas bibliotecas escolares, é o único meio de aquisição de materiais para composição da coleção, e por isso os critérios estabelecidos em sua seleção são complexos, pois contemplarão usuários e contextos por todo o país, considerando toda sua diversidade cultural.

O sistema de seleção das obras que comporão os acervos do PNBE a serem enviados às escolas opera por meio de Edital publicado pelo FNDE anualmente, estabelecendo os requisitos de inscrição e os respectivos requisitos de seleção das obras. Os editais a partir de 2003 são disponibilizados no site do FNDE, os anteriores por sua vez, não estão disponíveis para consulta.

Segundo Fernandes e Cordeiro (2012, p. 327) "os editais, de modo geral, ressaltam a importância de oferecer diferentes tipos de leitura aos alunos de escola pública, com diversidade de autores, gêneros, temáticas, técnicas de ilustrações e representações culturais, o que é fundamental", mesmo que inicialmente os critérios de seleção não estivessem claramente apontados em nenhuma publicação oficial, a cada nova edição os gestores têm apresentado um aprimoramento tanto dos mesmos como de sua enunciação e descrição, diminuindo a ocorrência de ambiguidades e falta de transparência.

A partir do PNBE-2001 foram apresentadas, basicamente, duas outras exigências, a diversidade de representação literária, e a materialidade (padrões de qualificação gráfica e de ilustração), sendo avaliadas de acordo com o público-alvo (FERNANDES; CORDEIRO, 2012).

Como normas gerais, desde o edital de 2005, encontraram-se as seguintes prerrogativas:

O acervo será composto por obras de diferentes níveis de dificuldade, de forma que os alunos leitores tenham acesso a textos para serem lidos com autonomia e outros para serem lidos com a mediação do professor. A qualidade do texto, a adequação temática, a representatividade das obras e os aspectos gráficos serão considerados critérios indispensáveis para a seleção de uma determinada obra. (BRASIL, 2004, p. 13) 
Políticas públicas para a biblioteca escolar e o fortalecimento da identidade regional brasileira: as contribuições do PNBE

Quanto à qualidade do texto, avaliam-se as qualidades textuais básicas e o trabalho estético com a linguagem, e ainda se os textos caracterizam-se como instrumentos capazes de ampliar o repertório linguístico dos leitores, autonomamente e com a mediação do professor (BRASIL, 2012). Buscam-se temáticas diversificadas, que enunciem contextos diversos quanto aos aspectos sociais, culturais e históricos, mas que evitem qualquer tipo de discriminação e preconceitos (BRASIL, 2005).

A representatividade é explicitada no PNBE-2005:

[...] os títulos devem ser representativos de diferentes propostas e programas literários - desde aqueles que já firmaram uma tradição e conquistaram o reconhecimento de diferentes instâncias da instituição literária, àqueles que rompem com esta tradição e propõem - contemporaneamente - novos modelos e princípios para a produção literária.BRASIL, 2004, p. 14

Isso mostra o cuidado com a composição de um acervo à altura da cultura brasileira, ou seja, que seja multicultural e com a preocupação de contemplar as obras atemporais e contemporâneas, que apresentem "além da diversidade temática, os diferentes contextos socioeconômicos, culturais, ambientais e históricos que constituem a sociedade brasileira”(BRASIL, 2009, p. 28).

Os projetos gráficos têm sido avaliados de acordo com a adequação ao contexto literário da obra, como a sua expressividade. Ressalta-se também que "a biografia do(s) autor(es) deve ser apresentada de forma a enriquecer o projeto gráfico e promover a contextualização do autor e da obra no universo literário” (BRASIL, 2007, p. 15).

Ao estabelecer essas prerrogativas, o PNBE, como afirmam Fernandes e Cordeiro (2012, p. 325-326), "ressalta a necessidade de proporcionar aos leitores variedade de livros que levem em conta a abordagem de diferentes meios culturais, sociedades, tradições e problemas do mundo, buscando construir condições para que os estudantes desenvolvam consciência crítica em prol de novas e melhores relações sociais".

Percebe-se que:

Em linhas gerais, pôde-se observar nos editais estudados que os critérios de avaliação e seleção do PNBE foram se tornando cada vez mais minuciosos, o que não deixa dúvidas acerca da seriedade do programa e dos profissionais envolvidos. Por se tratar de um programa federal, é fundamental destacar que o PNBE foi mantido, ampliado e aprimorado ao longo de sua existência. (FERNANDES; CORDEIRO, 2012, p. 327).

Assim as escolas, e consequentemente as bibliotecas escolares que têm sido contempladas com as coleções do PNBE, possibilitando que o "estudante tenha sempre ao seu

Bibl. Esc. em R., Ribeirão Preto, v. 6, n. 1, p. 18-42, 2018. 
alcance um universo de opções que possa ser lido, compreendido e assimilado, tudo isso representa, em verdade, recriar um país, redescobrir suas potencialidades" (MACIEL, $2008^{1}$ apud FERNANDES; CORDEIRO, 2012 p. 327).

Ao analizar os critérios estabelecidos ao longo dos anos de execução do programa, verificou-se que há a preocupação com a valorização da diversidade cultural que compõe o Brasil, pois "o desafio é valorizar o que somos segundo nosso próprio referencial. Ter a convicção de onde podemos chegar conforme nossos próprios valores" (BRANT, 2005, p. 22).

Llosa, (2004² apud BRANT, 2005, p. 30) afirma que:

Os produtos culturais devem ser objeto de um cuidado especial por parte do Estado, pois deles depende, de maneira primordial, a identidade de um povo, ou seja, sua alma, seu espírito, aquilo que o singulariza entre os outros e constitui o denominador comum entre seus cidadãos: seus padrões estéticos, sua identificação com uma tradição e um modo de ser, sentir, crer, sonhar, em suma, o aglutinante moral, intelectual e espiritual da sociedade.

Faz-se necessário assim estabelecer a relação prática entre as ações do programa e a formação da identidade cultural regional brasileira, percebendo as contribuições do mesmo para o desenvolvimento e fortalecimento da sociedade brasileira.

\section{A relação entre os acervos distribuídos pelo pnbe e a concepção de formação da identidade regional brasileira}

Enquanto elemento essencialmente humano, a cultura torna possível a transformação social, assim sendo, requer-se que esta seja estimada e protegida, pois cada cultura exprime um modo único de se pensar socialmente (CUCHE, 2002).

Para Beltrame (2005, p. 59) "a cultura de cada povo apresenta os elementos pelos quais ele se adapta e reage a seu tempo", e é exatamente por isso que o PNBE explicita que:

As crianças que chegam à escola - tanto as que ingressam na educação infantil
quanto aquelas que ingressam no ensino fundamental - são provenientes de
contextos sócio-culturais diferentes e, por isso, possuem experiências diferenciadas
de contatos com a leitura e a escrita. Os acervos de obras de literatura, além da
qualidade e valor artístico, deverão contar com títulos temática e esteticamente

\footnotetext{
${ }^{1}$ MACIEL, F. I. P. O PNBE e o Ceale: como semear leituras. In: PAIVA, A.; SOARES, M. (Org.). Literatura infantil: políticas e concepções. Belo Horizonte: Autêntica, 2008, p. 07-20.

${ }^{2}$ LLOSA, Mario Vargas. Globalização e Cultura Nacional. O Estado de São Paulo, 1 Ago. 2004.
}

Bibl. Esc. em R., Ribeirão Preto, v. 6, n. 1, p. 18-42, 2018. 
Políticas públicas para a biblioteca escolar e o fortalecimento da identidade regional brasileira: as contribuições do PNBE

diversos, capazes de aproximar as crianças das diferentes realidades e de ampliar suas experiências de leitura. (BRASIL, 2007, p. 14)

Essa preocupação demonstra a consonância entre o projeto do programa com o que Hall (2003, p. 51) defende:

As culturas nacionais, ao produzirem sentidos sobre 'a nação', sentidos com os quais podemos nos identificar, constroem identidades. Esses sentidos estão contidos nas estórias que são contadas sobre a nação, memórias que conectam seu presente com seu passado e imagens que dela são construídas.

A construção da identidade seja ela individual ou social, regional ou nacional, está continuamente em processo de construção e transformação (MORETTINI; URT, 2010), o que caracteriza a própria sociedade moderna (HALL, 2003), e por ser influenciada inevitavelmente pela cultura, é preciso a preservação dos bens culturais, o que como Meneses (2004, p. 182) afirma, "pressupõe sempre uma continuidade, uma disponibilidade permanente, em função precisamente da alimentação da identidade cultural”.

"O suporte fundamental da identidade é a memória, mecanismo de retenção de informação, conhecimento, experiência, quer em nível individual, quer social e, por isso mesmo, é eixo de atribuições, que articula, categoriza os aspectos multiformes de realidade, dando-lhes lógica e inteligibilidade" (MENEZES, 2004, p.183), e a literatura como elemento de memória e registro da cultura, deve ser disponibilizada a todos os cidadãos através da educação, pois é por meio desta que "se dá a aquisição da cultura humana às novas gerações" (MORETTINI; URT, 2010 p. 72) e porque "a literatura é um patrimônio cultural a que todos os cidadãos devem ter acesso" (BRASIL, 2009, p. 25).

Santos $\left(1986^{3}\right.$, p. 50 apud MORETTINI; URT, 2010) define cultura como a dimensão que inclui todo o conhecimento de uma sociedade, mas num sentido ampliado e ao mesmo tempo inclui também as maneiras como esse conhecimento é expresso, da mesma forma para o Ministério da Educação (MEC) enquanto responsável pelo PNBE:

A diversidade de ambientes sociais presentes nos livros de literatura busca, a um tempo, considerar como o público leitor poderá ver sua realidade retratada, elaborada e recriada de forma literária nos livros, bem como permitir o conhecimento desta variedade cultural e social por parte do público mais amplo, contribuindo desta forma para uma visão mais complexa e diferenciada da sociedade brasileira(BRASIL, 2009, p. 27).

O programa em suas diretrizes busca reduzir, como mostrado anteriormente, as desigualdades, pois como Morettini e Urt (2010, p. 76) afirmam a "desigualdade existente

\footnotetext{
${ }^{3}$ SANTOS, J. L. dos. O que é cultura. 5. Ed. São Paulo: Brasilense, 1986.

Bibl. Esc. em R., Ribeirão Preto, v. 6, n. 1, p. 18-42, 2018.
} 
entre os homens é produto da desigualdade econômica, das diferenças de classes e consequentemente das diferentes formas de apropriação das aquisições humanas", aquisições estas, que são transmitidas através do acesso aos bens culturais.

Posto que a cultura é um elemento chave na construção da identidade, e que claramente, para o MEC :

[...] é dever do Estado garantir aos alunos e professores da rede pública de ensino o pleno acesso à cultura e à informação, promovendo a inserção desses alunos no universo cultural, de forma a contribuir para a construção de referenciais éticos e estéticos e de ampliar a visão de mundo, formando, assim, indivíduos independentes e críticos, em interação com uma sociedade cidadã. (BRASIL, 2010, p. 22)

Que cultura é essa que está acessível aos alunos e professores atendidos pelo PNBE? Hall (2003) chama a atenção de forma simplificada que apesar das diferenças inerentes aos membros de uma nação, a cultura "nacional" pode buscar unificá-los numa identidade cultural, ao defender o seu próprio fortalecimento perante a globalização, mas ao mesmo tempo o autor questiona se "seria a identidade nacional uma identidade unificadora desse tipo, uma identidade que anula e subordina a diferença cultural” (HALL, 2003, p. 59).

O desafio que se propõe, portanto, dentro das sociedades modernas, que tem fragmentado as paisagens culturais, abalando a ideia que o indivíduo tem de si próprio (HALL, 2003) "é valorizar o que somos segundo nosso próprio referencial. Ter a convicção de onde podemos chegar conforme nossos próprios valores" (BRANT, 2005, p. 22).

Logo, para que o PNBE contemple a multiculturalidade brasileira, e promova relacionamentos "em um contexto cada vez mais multicultural e heterogêneo embora a pressão homogeneizadora se faça presente" (MORETTINI; URT, 2010, p. 73), a "identidade nacional" (dita pura, e una) não deve ser exaltada, pois pode levar "a uma tentativa de subversão simbólica contra a afirmação da identidade" (CUCHE, 2002, p. 189), isso porque, "seria não levar em conta a heterogeneidade de todo grupo social" (CUCHE, 2002, p. 192).

Segundo Álvarez (2005, p. 173) “o Brasil, na condição de país que tem o privilégio de deter uma diversidade natural e cultural riquíssima, considera também fundamental a questão da proteção dos conhecimentos tradicionais [...]", e esses saberes estão inseridos na diversidade cultural do país, que diferem em cada região, mas que juntos compõem a "cultura brasileira”. Essa diversidade é o que fortalece a Identidade Regional, sendo que para este 
Políticas públicas para a biblioteca escolar e o fortalecimento da identidade regional brasileira: as contribuições do PNBE

trabalho, assumimos o conceito estabelecido por Tajfel (1981 ${ }^{4}$ apud SOUZA; GIL, 2015, p. 481) onde "identidade regional refere-se ao autoconceito de um indivíduo, que deriva do conhecimento de sua pertença a um grupo junto com o significado emocional e avaliativo desse pertencimento".

Dessarte, "o país deseja que a diversidade cultural seja não só reconhecida e valorizada, como também possa vicejar em condições de equidade, liberdade e dignidade" (ÁLVAREZ, 2005, p. 172), e como “direitos culturais, igualdade de oportunidades e políticas de inclusão estão inevitavelmente vinculados para que a diversidade cultural possa se fortalecer" (ÁLVAREZ, 2005, p.172), políticas públicas como o PNBE devem contemplar essa diversidade.

Procedeu-se então a avaliação de uma amostra do programa, para perceber a sua contribuição para o fortalecimento da cultura regional através do incentivo a leitura de autores das diversas regiões do país, bem como da temática e contextos apresentados nas obras selecionadas e distribuídas, pois “[...] o objetivo da avaliação de política pública é conhecer seus fatores positivos, apontar seus equívocos e insuficiências, com a finalidade de buscar seu aperfeiçoamento ou reformulação" (BELLONI; MAGALHÃES; SOUZA, 2000, p.45).

\section{Material e Métodos}

A pesquisa caracterizou-se como exploratória, com "ênfase dada à descoberta de práticas ou diretrizes que precisam modificar-se e na elaboração de alternativas que possam ser substituídas" (OLIVEIRA, 2001, p. 134), tendo por "objetivo de reunir dados, informações, padrões, idéias ou hipóteses sobre um problema ou questão de pesquisa com pouco ou nenhum estudo anterior" (BRAGA, 2007, p. 25).

Como instrumento de coleta de dados utilizou-se das fontes primárias de informação produzidas pelos órgãos responsáveis pela implementação do PNBE, tais como a portaria de criação, os editais anuais de seleção, o Diário Oficial da União, a página oficial do FNDE, e por fim, parte das obras.

Para verificar se o PNBE como uma política pública, tem contribuído para a construção da identidade regional brasileira por meio dos acervos selecionados e distribuídos

\footnotetext{
${ }^{4}$ TAJFEL, H. Grupos humanos e categorias sociais. Lisboa: Livros Horizonte, 1981. v. I e II.
}

Bibl. Esc. em R., Ribeirão Preto, v. 6, n. 1, p. 18-42, 2018. 
para as escolas e disponibilizados nas bibliotecas escolares, utilizou-se da pesquisa documental que:

[...] corresponde a toda a informação coletada, seja de forma oral, escrita ou visualizada. Ela consiste na coleta, classificação, seleção difusa e utilização de toda a espécie de informações, compreendendo também as técnicas e os métodos que facilitam a sua busca e a sua identificação. (FACHIN, 2006, p. 146)

Aplicou-se, ainda, ao estudo do programa, a pesquisa qualitativa, pois esta, segundo Minayo (2007 ${ }^{5}$ apud CAVALCANTE; CALIXTO; PINHEIRO, 2014, p. 14) “proporciona um modelo de entendimento profundo de ligações entre elementos, direcionado à compreensão da manifestação do objeto de estudo". Essa abordagem permitirá a descrição da complexidade do problema, permitindo compreender e classificar processos dinâmicos, além de apresentar contribuições no processo de mudança, criação ou formação (OLIVEIRA, 2001).

Realizou-se o levantamento das obras selecionadas no ano de 2013 do programa, especificamente para os acervos enviados às bibliotecas escolares, onde utilizando da análise de conteúdo buscou-se compreender as sociedades representadas no texto literário, bem como o nível de representatividade das obras conforme as regiões.

Para Cavalcante, Calixto e Pinheiro (2014, p. 14) "a análise de conteúdo compreende técnicas de pesquisa que permitem, de forma sistemática, a descrição das mensagens e das atitudes atreladas ao contexto da enunciação, bem como as inferências sobre os dados coletados", essas técnicas são compreendidas basicamente em três fases: a pré-análise que compreende a leitura global do material selecionado, a codificação para definição de regras de contagem e a classificação e agregação das informações em categorias simbólicas, e por fim a fase de interpretação (SILVA; FOSSÁ, 2013).

Dentre os acervos distribuídos no ano de 2013, foram definidos como amostra para a análise os acervos distribuídos aos Anos Finais do Ensino Fundamental ( $6^{\circ}$ ao $9^{\circ}$ ano), sendo que cada acervo é composto por 60 títulos, e foram disponibilizados três acervos diferentes, dentre os quais cada escola recebeu dois (totalizando 120 obras).

Para ter acesso aos acervos, e verficar quais deles foram efetivamente recebidos, pesquisou-se no município de Sidrolândia - MS, em todas as escolas de ensino fundamental listadas nos relatórios de distribuição disponíveis no site do FNDE. Das escolas da rede municipal, em apenas uma foi constatado o recebimento do acervo, mas este se encontrava

\footnotetext{
${ }^{5}$ MINAYO, M.C.S. O desafio do conhecimento: pesquisa qualitativa em saúde. 10. ed. São Paulo: HUCITEC, 2007. 406 p.
} 
Políticas públicas para a biblioteca escolar e o fortalecimento da identidade regional brasileira: as contribuições do PNBE

localizado em uma sala que no momento estava interditada pela defesa civil por estabelecer risco, já na rede estadual apenas uma das escolas declarou ter biblioteca escolar e disponibilizar os acervos aos alunos, portanto esses acervos foram os selecionados.

$\mathrm{Na}$ escola selecionada foram recebidos os títulos referentes aos acervos 1 e 3, compreendendo 120 títulos, onde após verificação de quais destes encontravam-se disponíveis na biblioteca foram localizados 60 títulos, que compreendiam em 26 do acervo 1 e 34 do acervo 3, os quais foram submetidos à análise de conteúdo, com o objetivo de perceber se as prerrogativas do programa, no que diz respeito à formação e ao acesso à diversidade cultural através do acervo disponibilizado às bibliotecas escolares, tem sido ativa. Os demais títulos dos referidos acervos não foram analisados devido à sua indisponibilidade nas demais escolas do município pesquisado.

\section{Resultados e análise dos dados}

Dentre os livros distribuídos pelo PNBE 2013 - Anos Finais do Ensino Fundamental, foram submetidos à análise 60 títulos, onde após a pré-análise foram classificados inicialmente em Nacional (títulos que o contexto representado na obra trate de realidades nacionais) e Internacional (títulos que o contexto representado na obra trate de realidades internacionais) como mostra o Quadro 1.

Quadro 1 - Classificação inicial de parte das obras dos Acervos 1 e 3 dos Anos Finais do Ensino Fundamental de 2013

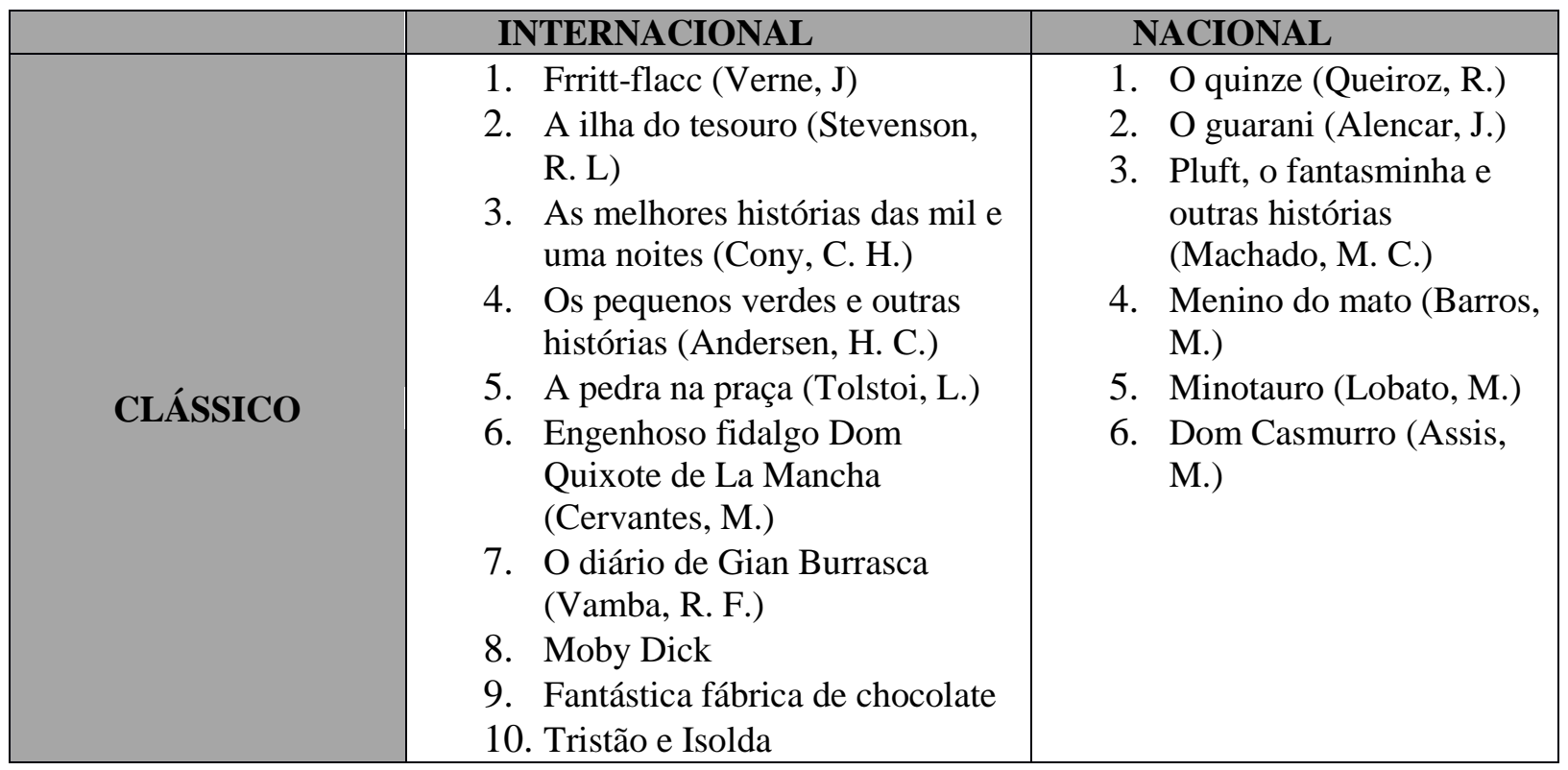

Bibl. Esc. em R., Ribeirão Preto, v. 6, n. 1, p. 18-42, 2018. 


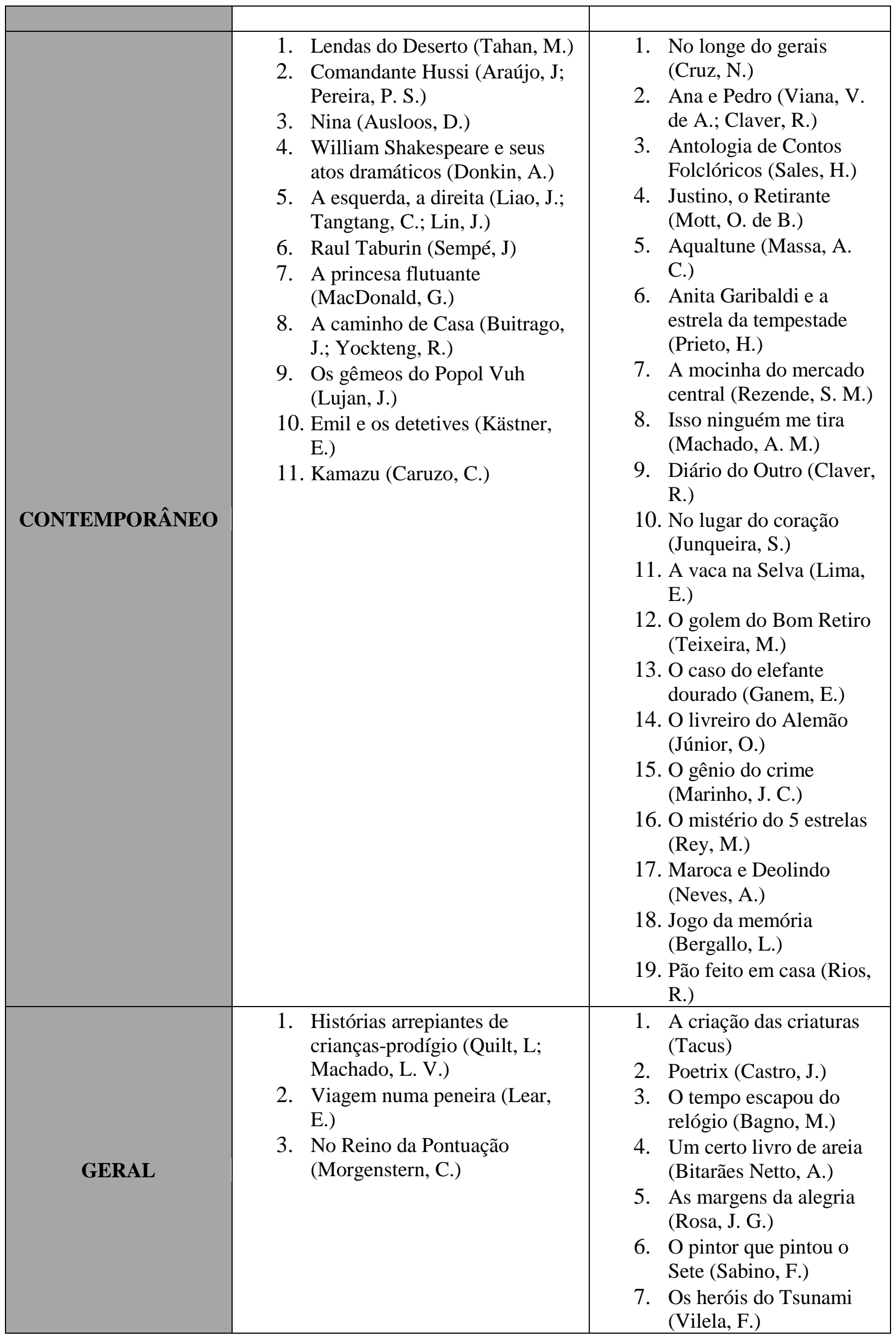


Políticas públicas para a biblioteca escolar e o fortalecimento da identidade regional brasileira: as contribuições do PNBE

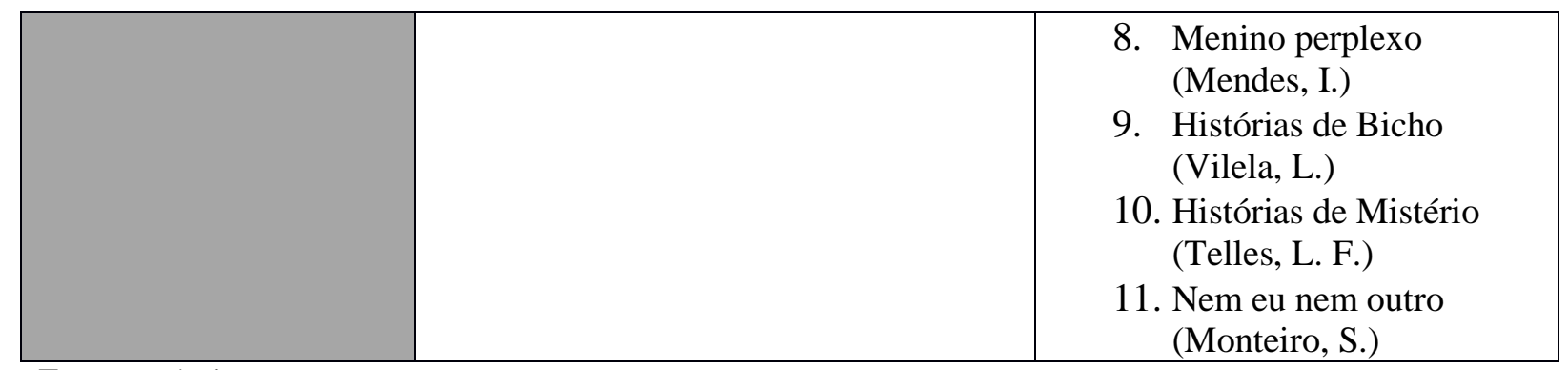

Fonte: Própria

Percebeu-se que, dentre as obras selecionadas pelos gestores do PNBE, a amostra é composta por uma proporção de $60 \%$ de títulos nacionais e $40 \%$ internacionais, atingindo um dos critérios do programa, pois "os acervos serão compostos por obras de diferentes tipos e gêneros literários, de forma a fornecer aos leitores um panorama da literatura brasileira e estrangeira" (BRASIL, 2011, p. 21).

Para verificar, a contribuição para o fortalecimento da identidade regional, as obras nacionais foram categorizadas em Clássicos (livros que fazem parte da literatura clássica nacional e internacional), Contemporâneos (livros que transmitem os mais diversos contextos culturais na atualidade) e Gerais (livros que não descrevem especificamente algum aspecto cultural, mas tratam de temas transversais) (ver Quadro 1).

Dentre as obras que trouxeram em sua temática o contexto cultural brasileiro, constam aproximadamente $18 \%$ de Clássicos, permitindo ao leitor "ampliar as referências estéticas, culturais" (BRASIL, 2011, p. 22), 30\% de obras gerais que possibilitam a "reflexão sobre a realidade, sobre si mesmo e sobre o outro" (BRASIL, 2011, p. 22), e mais da metade de obras Contemporâneas.

Para a categoria de obras Contemporâneas foram classificados os títulos (além dos Clássicos) que representam de alguma forma os diversos contextos sociais do Brasil, que são elementos essenciais para o fortalecimento da identidade regional, os quais estão descritos no quadro a seguir:

Quadro 2 -Distibuição dos títulos contemporâneos do PNBE-2013 (Amostra)

\begin{tabular}{|c|c|c|}
\hline TITULO & ZONA & $\begin{array}{c}\text { Estado } \\
\text { (Quando especificado) }\end{array}$ \\
\hline No longe dos gerais & Rural & MG \\
\hline Ana e Pedro & Urbana & MG/SP \\
\hline Antologia de Contos Folclóricos & Rural & Brasil \\
\hline Justino, o Retirante & Rural & CE \\
\hline Aqualtune & Rural & AL \\
\hline Anita Garibaldi e a estrela da tempestade & Urbana & SC \\
\hline
\end{tabular}

Bibl. Esc. em R., Ribeirão Preto, v. 6, n. 1, p. 18-42, 2018. 


\begin{tabular}{|c|c|c|}
\hline A mocinha do mercado central & Urbana & MG \\
\hline Isso ninguém me tira & Urbana & RJ/SP \\
\hline Diário do Outro & Urbana & MG \\
\hline No lugar do coração & Rural & - \\
\hline A vaca na Selva & Selva & SP \\
\hline O golem do Bom Retiro & Urbana & RJ/SP \\
\hline O caso do elefante dourado & Urbana & RJ \\
\hline O livreiro do Alemão & Urbana & SP \\
\hline O gênio do crime & Urbana & Brasil \\
\hline O mistério do 5 estrelas & Urbana & - \\
\hline Maroca e Deolindo & - & - \\
\hline Jogo da memória & Urbana & Urbana \\
\hline Pão feito em casa & &
\end{tabular}

Fonte: Própria.

A classificação do Quadro 2, refere-se ao contexto apresentado no texto das obras, onde a coluna 'Zona' refere-se a histórias que são ambientadas no meio rural, trazendo características locais e do interior, ou urbana, apresentando as nuances dos diversos ambientes que coexistem dentro das cidades. A coluna 'Estado' refere-se à localidade tratada na obra, quando explicitada no texto, mas conta ainda com algumas obras que ou se referem a diversos Estados ou a nenhum em específico.

Como é possível observar, existe uma predominância (no acervo do PNBE - 2013) de mais de $60 \%$ em contextos sociais urbanos, e destes, mais de $50 \%$ são distribuídos pela região sudeste. Esse aspecto demonstra de maneira clara que apesar de um dos critérios de seleção ser o de "obras com temáticas diversificadas, de diferentes contextos sociais, culturais e históricos" este não é eficazmente respeitado, uma vez que há pouca ou quase nenhuma representação cultural, social e histórica das outras regiões.

Apesar disso, durante a análise das obras, constatou-se que os contextos urbanos são diversos, e exploram a multiculturalidade existente muitas vezes de uma única cidade.

"O Golem do Bom Retiro" retrata a cultura judaica ortodoxa vivida pelos imigrantes no estado de São Paulo, seus contrastes, lendas e, ainda, o preconceito e perseguição sofridos por eles. Percebe-se que a obra discute temas como a violência, os movimentos de contracultura, que podem ser usadas para fazer uma comparação com a questão imigratória da atualidade.

Os dilemas dos imigrantes que vieram para o Brasil fugindo de guerras continuam a ser apresentados em "Jogo da Memória" que ao mesmo tempo evidencia as dificuldades 
Políticas públicas para a biblioteca escolar e o fortalecimento da identidade regional brasileira: as contribuições do PNBE

enfrentadas por pessoas atingidas pela doença de Alzeimer e suas famílias, proporcionando o desenvolvimento nos leitores "[da] capacidade de reflexão diante de si, do outro e do mundo que o cerca” (BRASIL, 2012, p. 21).

"Anita Garibaldi e a estrela da Tempestade" ao mostrar as relações e papéis sociais durante a Guerra dos Farrapos e a luta dos revolucionários contra a monarquia, descreve os costumes sociais da época e ao mesmo tempo critica alguns padrões impostos. A obra permite assim, a compreensão de parte da construção histórico - social de Santa Catarina.

A realidade de parte das comunidades do Rio de Janeiro é o contexto da biografia de Otávio Júnior, em "O livreiro do Alemão", mostrando aos leitores a transformação pessoal e social vivida por meio do acesso aos livros e a leitura, expressando dentro do próprio texto o objetivo do PNBE 2013 que é "que os alunos possam apropriar-se de práticas de leitura e escrita de forma a interagir com a cultura letrada disseminada socialmente, promovendo o pleno exercício da cidadania” (BRASIL, 2012, p. 21).

"Maroca e Deolindo" caracterizou-se por uma obra rica, "apresentando temáticas diversificadas, de diferentes contextos sociais, culturais e históricos" (BRASIL, 2012, p. 22), ao descrever de forma lúdica algumas festas típicas espalhadas pelo Brasil, através de 12 contos distribuídos pelos meses do ano.

Já nos contextos rurais, as obras selecionadas, apesar de em menor número, apresentam parte dos costumes e cultura do interior. Em "A vaca na Selva” a aventura da volta de um índio à sua tribo, elementos culturais indígenas e urbanos são confrontados, bem como a maneira diversa de se representar através da linguagem as coisas do dia-a-dia, contribuindo "para ampliar o repertório linguístico dos leitores e, ao mesmo tempo, propiciar a fruição estética" (BRASIL, 2012, p. 21).

Uma comunidade quilombola do estado de Alagoas é o contexto de "Aqualtune", revelando parte de suas tradições, lendas e crenças, apresentando aos leitores uma nuance da multiculturalidade brasileira.

Em “Antologia de contos folclóricos”, os contos apresentados são originários da tradição oral, e oferecem ao leitor uma perspectiva da religiosidade, do cotidiano do trabalho na zona rural, de comunidades ribeirinhas.

As comunidades sertanejas são o tema em "Justino o retirante", que explana a questão social do sertão nordestino, da migração provocada pela seca, e ainda versa sobre o 
coronelismo existente. Já em "No longe dos Gerais" a obra discorre sobre o transporte do gado feito pro vaqueiros pelo interior do estado de Minas Gerais, apresentando a culinária típica, a religiosidade, a arquitetura, a linguagem, parte da história, da fauna e da flora dessa região, enunciando "adequação do discurso das personagens a variáveis de natureza situacional e dialetal"(BRASIL, 2012, p. 21), que por sua vez enriquece a leitura, bem como “as referências estéticas, culturais e éticas do leitor”(BRASIL, 2012, p. 22).

Em geral as obras selecionadas enquadravam-se nos critérios de seleção estabelecidos nos editais, versando sobre a sociedade brasileira em seus múltiplos aspectos. Cotidianos diversos foram confrontados, mostrando que a construção cultural brasileira é diversa, e não pode ser explicada pela realidade de apenas uma de suas regiões.

Percebeu-se que as obras levam a reflexão da construção do cidadão brasileiro, através de suas influências religiosas, históricas e familiares, através da exemplificação de algumas sociedades e seus costumes como em "Ana e Pedro", "A mocinha do mercado central”, "Isso ninguém me tira", "Diário do outro", "No lugar do coração", "O caso do elefante dourado", "O gênio do Crime", "O mistério do 5 estrelas" e "Pão feito em casa".

As obras que foram classificadas como "Gerais" por sua vez, levam o leitor a conhecer aspectos estéticos literários, como a poesia em "Poetrix", "O tempo escapou do relógio" e "Menino Perplexo", ou a arte em "O pintor que pintou o sete" e a literatura em "Um certo livro de areia", mas também a instigar o estabelecimento de relações com experiências pessoais anteriores (BRASIL, 2012) e conscientizar o leitor para questões de importância social e moral ao refletir sobre si mesmo, por meio de obras como "O pão feito em casa", "Histórias de Mistério", "Os heróis do Tsunami”, "A criação das criaturas", “As margens da alegria", "Histórias de bicho" e "Nem eu nem outro".

Assim sendo, as obras analisadas, conseguiram, ainda que de forma limitada, apresentar parte da diversidade cultural brasileira,revelando nuances desse país continental. Por se tratar de um programa de longo prazo, que distribuiu obras durante 19 anos (desde 2014 não tem sido distribuido novos acervos), a sua contribuição foi imprescindível para as bibliotecas escolares, e consequentemente para os estudantes da rede pública de ensino. 
Políticas públicas para a biblioteca escolar e o fortalecimento da identidade regional brasileira: as contribuições do PNBE

\section{Conclusão}

O PNBE, desde que foi criado, revelou a preocupação do poder público em subsidiar as escolas e suas respectivas bibliotecas escolares com acervos de qualidade literária e gráfica, e assim proporcionar aos alunos da rede pública de ensino o acesso a instrumentos de cultura, diminuindo as diferenças sociais causadas pela marginalização de parte da sociedade brasileira.

Ao estudar o programa e sua evolução ao longo dos anos percebe-se o aprimoramento da seleção e distribuição das obras, os critérios de seleção foram estabelecidos e divulgados, bem como a distribuição passou a ser feita diretamente às escolas cadastradas através dos Correios, evitando a dispersão das obras em outros órgãos.

Apesar dos esforços do programa, por ser voltado apenas à disponibilização de obras, limita-se a construção da coleção e não ao seu uso propriamente dito. Para que a biblioteca escolar se torne um espaço de construção de cidadania não basta ter material de qualidade em suas estantes, é necessário o estabelecimento de uma política de dinamização do mesmo, tornando o acessível aos alunos. Um elemento essencial para que isso ocorra é o capital humano capaz de mediar o aprendizado dentro das bibliotecas, demandando um trabalho conjunto entre bibliotecários, técnicos e professores.

Cada vez mais, a formação continuada revela-se imprescindível, tanto de professores como dos bibliotecários, não se limitando ao trabalho técnico de cada uma das áreas, quer seja de ministrar aulas expositivas ou a organização do acervo, essenciais para a educação, mas que o conhecimento seja aplicado mediante o uso de técnicas de dinamização das aulas e da leitura, gerando novas oportunidades de produção de conhecimento e de autonomia do leitor.

O Brasil, enquanto nação, é caracterizado por um território continental, e tanto quanto o território a cultura do seu povo é tão diversa quanto as existentes em todo um continente, mas ao mesmo tempo possui traços específicos que fazem parte das identidades pessoais e regionais de sua sociedade. Para que essa identidade seja fortalecida, percebe-se o valor inestimável da memória que gera o sentimento de pertencimento e identificação necessário para criar as ligações entre o indivíduo e o seu contexto, e esta pode ser transmitida de diversas maneiras, seja oralmente, ou através de sua por meio da sua transposição imortalizada para os livros. 
A literatura é, comprovadamente, um instrumento de construção e perpetuação da cultura, e deve ser estimulada desde a infância. O objetivo desta pesquisa foi perceber se o PNBE contribuiu para o fortalecimento da identidade regional brasileira através das obras selecionadas e distribuídas às bibliotecas escolares, e ao analisar o conteúdo de parte das obras distribuídas no ano de 2013 aos Anos Finais do Ensino Fundamental, foi possível fazer algumas considerações.

O programa conseguiu apresentar aos alunos obras nacionais e internacionais, oportunizando o seu contato com o mundo literário, possibilitando a leitura de obras literárias clássicas e contemporâneas, e ainda algumas que levam o leitor à reflexão sobre si mesmo e sobre suas relações.

No que diz respeito a representatividade cultural brasileira, constatou-se que as obras proporcionam um contato maior com contextos da região sudeste, explorando pouco os costumes, contextos sociais e cultura de outras regiões. Apesar disso, as realidades apresentadas pelas obras são diversificadas, mostrando diversas nuances das microculturas que permeiam as cidades e regiões, mostrando que a cultura brasileira vai muito além do que se imagina.

Assim, notou-se, na amostra analisada, a carência de maior abertura para obras de autores menos conhecidos, de regiões não localizadas nas áreas metropolitanas, possibilitando a maior representatividade cultural, mas como tratou-se de um estudo exploratório serão necessários ainda novos esforços para uma compreensão mais aprofundada do programa.

Outro aspecto que pode ser explorado é a efetividade da distribuição, pois apesar desta ter sido direcionada diretamente às escolas através do serviço de correios, percebeu-se que muitas delas já não possuem os acervos recebidos, e outras não notificam o recebimento, apesar de constar em meios oficiais.

Por fim, o caminho para mudar a realidade da biblioteca escolar brasileira ainda é longo, são necessárias mais políticas públicas e a conscientização de sua importância para a formação dos alunos enquanto verdadeiros cidadãos com consciência crítica. E ainda resta a incógnita se a única política em âmbito federal voltará a ser exercida, uma vez que se encontra interrompida desde 2014. 
Políticas públicas para a biblioteca escolar e o fortalecimento da identidade regional brasileira: as contribuições do PNBE

\section{Referências}

ABREU, V. L. F. G. Pesquisa escolar. In: CAMPELLO, B. S. A biblioteca escolar: temas para uma prática pedagógica. 2. ed. Belo Horizonte: Autêntica, 2003, p. 29-32.

ALENCAR, C. Um povo de leitores. In: AMORIM, G. (Org.). Políticas públicas do livro e leitura. Brasília, DF: OEI; São Paulo: Cultura Acadêmica, 2006.

ÁLVAREZ, V. C. Diversidade cultural: algumas considerações. In: BRANT, L. (Org.). Diversidade cultural: globalização e culturas locais: dimensões, efeitos e perspectivas. São Paulo: Escrituras: Instituto Pensarte, 2005. p. 167-172.

BELLONI, I.; MAGALHÃES, H.; SOUSA, L. C. Metodologia de avaliação em políticas públicas: uma experiência em educação profissional. São Paulo: Cortez, 2000.

BELTRAME, P. Globalização e cultura, processos da indústria cultural em escala mundial. In: BRANT, L. (Org.). Diversidade cultural: globalização e culturas locais: dimensões, efeitos e perspectivas. São Paulo: Escrituras: Instituto Pensarte, 2005, p. 57-72.

BRAGA, K. S. Aspectos relevantes para a seleção de metodologia adequada à pesquisa social em Ciência da Informação. In: MULLER, S. P. M. (Org.). Métodos para pesquisa em Ciência da Informação. Brasília: Thesaurus, 2007.

BRANT, L. (Org.). Diversidade cultural: globalização e culturas locais: dimensões, efeitos e perspectivas. São Paulo: Escrituras: Instituto Pensarte, 2005.

BRASIL. Ministério da Educação. Fundo Nacional de Desenvolvimento da Educação. Programa Nacional Biblioteca da Escola. Apresentação. [Brasília, DF: 2014?a]. Disponível em: <http://www.fnde.gov.br/programas/biblioteca-da-escola/biblioteca-da-escolafuncionamento $>$. Acesso em: 25 mar. 2016.

. Estatísticas. [Brasília, DF: 2014?b]. Disponível em: $<$ http://www.fnde.gov.br/programas/biblioteca-da-escola/biblioteca-da-escolafuncionamento>. Acesso em: 25 mar. 2016.

Funcionamento. [Brasília, DF: 2014?c]. Disponível em:

<http://www.fnde.gov.br/programas/biblioteca-da-escola/biblioteca-da-escolafuncionamento>. Acesso em: 25 mar. 2016.

BRASIL. Ministério da Educação. Secretaria de Educação Básica, Coordenação-Geral de Materiais Didáticos. Programa Nacional Biblioteca da Escola (PNBE): leitura e bibliotecas nas escolas públicas brasileiras.Brasília, DF: Ministério da Educação, 2008.

BRASIL. Ministério da Educação e do Desporto. Portaria Ministerial n. 584, de 28 de abril de 1997. Diário Oficial [da] República Federativa do Brasil, Brasília, DF, 29 abr. 1997. Seção 1, p. 8519. Disponível em: <http://www.abrelivros.org.br/home/index.php/pnbe/5334portaria-n.\%C2\%BA-584-de-28-de-abril-de-1997>. Acesso em: 28 set. 2015.

BRASIL. Ministério da Educação. Fundo Nacional de Desenvolvimento da Educação. Edital de convocação para inscrição de obras de literatura no processo de avaliação e seleção 
para o Programa NacionalBiblioteca da Escola - PNBE/2005. Brasília, 2004. Disponível em: <http://www.fnde.gov.br/programas/biblioteca-da-escola/biblioteca-da-escolaconsultas/item/3017-editais-anteriores >. Acesso em: 13 maio 2016.

Edital de convocação para inscrição de obras de literatura a serem distribuidas às escolas públicas do ensino fundamental, no processo de avaliação e seleção para o Programa Nacional Biblioteca da Escola - PNBE/2006. Brasília, 2005. Disponível em: <http://www.fnde.gov.br/programas/biblioteca-da-escola/biblioteca-da-escolaconsultas/item/3017-editais-anteriores>. Acesso em: 13 maio 2016.

Edital de convocação para inscrição de obras de literatura no processo de avaliação e seleção para o Programa Nacional Biblioteca da Escola - PNBE 2008. Brasília, 2007. Disponível em: <http://www.fnde.gov.br/programas/biblioteca-daescola/biblioteca-da-escola-consultas/item/3017-editais-anteriores $>$. Acesso em: 13 maio 2016.

Edital de convocação para inscrição de obras de literatura no processo de avaliação e seleção para o Programa Nacional Biblioteca da Escola - PNBE 2010. Brasília, 2009. Disponível em: <http://www.fnde.gov.br/programas/biblioteca-daescola/biblioteca-da-escola-consultas/item/3017-editais-anteriores $>$. Acesso em: 13 maio 2016.

Edital de convocação para inscrição de obras de literatura no processo de avaliação e seleção para o Programa Nacional Biblioteca da Escola - PNBE/2013. Brasília, 2011. Disponível em: <http://www.fnde.gov.br/programas/biblioteca-daescola/biblioteca-da-escola-consultas/item/3980-edital-pnbe-2013 > . Acesso em: 13 maio 2016.

Edital de convocação para inscrição de obras de literatura no processo de avaliação e seleção para o Programa NacionalBiblioteca da Escola - PNBE/2014. Brasília, 2012. Disponível em: <http://www.fnde.gov.br/programas/biblioteca-daescola/biblioteca-da-escola-consultas/item/3017-editais-anteriores $>$. Acesso em: 13 maio 2016.

BUARQUE, C. Caminho mágico. In: AMORIM, G. (Org.). Políticas públicas do livro e leitura. Brasília: OEI; São Paulo: Cultura Acadêmica, 2006, p. 39-44.

CAMPELLO, B. S. A biblioteca escolar: temas para uma prática pedagógica. 2. ed. Belo Horizonte: Autêntica, 2003.

CAVALCANTE, R. B.; CALIXTO, P.; PINHEIRO, M. M. K. Análise de conteúdo: considerações gerais, relações com a pergunta de pesquisa, possibilidades e limitações do método. Informação \& Sociedade: Estudos, João Pessoa, v. 24, n. 1, p. 13-18, jan./abr. 2014. Disponível em: 〈http://www.ies.ufpb.br/ojs/index.php/ies/article/view/10000/10871>. Acesso em: 10 out. 2016.

CUCHE, D. A noção de cultura nas ciências sociais. 2. ed. Bauru: EDUSC, 2002.

FACHIN, O. Fundamentos de metodologia. 5. ed. rev. ampl. São Paulo: Saraiva, 2006 
Políticas públicas para a biblioteca escolar e o fortalecimento da identidade regional brasileira: as contribuições do PNBE

FERNANDES, C. R. D.; CORDEIRO, M. B. S. Os critérios de avaliação e seleção do PNBE: um estudo diacrônico. Educação, Porto Alegre, v. 35, n. 3, p. 319-328, set./dez. 2012.

HALL, S. A identidade cultural na pós-modernidade. 8. ed. Rio de Janeiro: DP\&A, 2003.

MARQUES NETO, J. C. Ano ibero-americano da leitura, o ano que não deve acabar. In: AMORIM, G. (Org.). Políticas públicas do livro e leitura. Brasília: OEI; São Paulo: Cultura Acadêmica, 2006, p. 19-29.

MENESES, U. B. Identidade cultural e arqueologia. In: BOSI, A. (Org.). Cultura brasileira: temas e situações. 4. ed. São Paulo: Ática, 2004. p. 182-190.

MORETTINI, M. T.; URT, S. C. Cancioneiro do Pantanal. Campo Grande: Life, 2010.

OLIVEIRA, S. L. Tratado de metodologia científica: projetos de pesquisas, TGI, TCC, monografias, dissertações e teses. 2. ed. São Paulo: Pioneira Thomson Learning, 2001

ROSA, F. G. M. G. Políticas públicas para o livro, leitura e biblioteca. Ciência da Informação, Brasília, v. 35, n. 3, p. 183-193, set./dez. 2006.

SILVA, A. H.; FOSSÁ, M. I. T. Análise de conteúdo: exemplo de aplicação da técnica para análise de dados qualitativos. ENCONTRO DE ENSINO E PESQUISA EM ADMINISTRAÇÃO E CONTABILIDADE, 4., 2013, Brasília. [Trabalhos apresentados]. Brasília: ANPAD, 2013. Disponível em: <http://www.anpad.org.br/diversos/trabalhos/EnEPQ/enepq_2013/2013_EnEPQ129.pdf>. Acesso em: 10 nov. 2016.

SILVA, W. C. Miséria da biblioteca escolar. São Paulo: Cortez, 1995.

SOUZA, D. A.; GIL, A. C. A importância da identidade regional na configuração de clusters turísticos. Turismo em Análise, São Paulo, v. 26, n. 2, p. 475-492, abr. 2015. Disponível em: <http://dx.doi.org/10.11606/issn.1984-4867.v26i2p475-492>. Acesso em: 11 nov. 2016.

VERGUEIRO, W. A linguagem dos quadrinhos: uma "alfabetização" necessária. In: RAMA, Â.; VERGUEIRO, W. (Org.). Como usar as histórias em quadrinhos na sala de aula. 4. ed. São Paulo: Contexto, 2010. 